\title{
Transaction
}

\section{Supercritical Fluid-assisted Electroless Copper Plating of Aramid Film : The Influence of Surface Treatment}

\author{
Magali Belmas $^{* 1}$, Isao Tabata ${ }^{* 2}$, Kenji Hisada ${ }^{* 1}$, and Teruo Hori ${ }^{* 1}$ \\ ${ }^{* 1}$ Graduate School of Engineering, Fiber Amenity Engineering, University of Fukui, 3-9-1 Bunkyo, \\ Fukui 910-8507, Japan \\ ${ }^{* 2}$ Technical Department, University of Fukui, 3-9-1 Bunkyo, Fukui 910-8507, Japan
}

\begin{abstract}
A process of metalizing aramid fibers using supercritical $\mathrm{CO}_{2}\left(\mathrm{sc}-\mathrm{CO}_{2}\right)$ followed by electroless copper plating has been developed recently. However, some applications require larger conductive surfaces without losing any of aramid fibers qualities (heat and chemical resistance, high strength, high flexibility). In response to such requirements, we developed in our present study a method of plating aramid film after impregnating it with organometallic complexes using sc- $\mathrm{CO}_{2}$ as a medium. In order to achieve uniform plating coupled with a high adhesiveness of the plated layer, two factors were examined. The impregnated Pd was reduced by two agents, $\mathrm{NaBH}_{4}$ in aqueous solution and $\mathrm{H}_{2}$ gas, in order to increase the amount of Pd metal present on the film surface. We found that the reduction of Pd did improve the plating of the aramid film. In spite of this, the adhesion of the shiny copper-colored layer had low strength.
\end{abstract}

(Received 28 May, 2010 ; Accepted 1 June, 2010)

\section{Introduction}

For over 50 years, plastic materials have been replacing metals in many different fields (automobiles, housing, safety and computers). Indeed, polymers are more versatile and can thus be modeled to exactly fit their new specific usages such as intelligent fibers or nano fibers. However, until recently, scientists faced the problem of the non-conductivity of polymers. Hence, they developed various metallization processes 1-3 to create smaller and lighter electrical devices.

With the realization that industrial waste leads to environmental problems 4 , new techniques have been developed to comply with new ecological legislation 5, 6 . Supercritical carbon dioxide $\left(\mathrm{sc}-\mathrm{CO}_{2}\right)$ is a widely used medium because of its intrinsic properties. $\mathrm{Sc}-\mathrm{CO}_{2}$ is completely recyclable, does not generate waste water and is an efficient replacement for many organic solvents 7 . Moreover, it has high diffusivity, low viscosity and high thermal conductivity, and is available at low cost. $\mathrm{Sc}-\mathrm{CO}_{2}$ addresses safety considerations as well, since it is nonflammable and non-reactive under most conditions. Due to those properties, $\mathrm{sc}-\mathrm{CO}_{2}$ is a valuable medium in the fields of extraction 8, dyeing 9 and impregnation 10. In the case of polymer impregnation, sc- $\mathrm{CO} 2$ plasticizes the matrix and swells it, thereby providing the room necessary to for the impregnation of solutes with relatively large molecular weights, such as organometallic complexes 11.

In this study, aramid film was impregnated with a palladium complex as a pre-treatment for electroless copper plating. This pre-treatment ensured the presence of Pd metal on the surface of the film and its action as catalyst during the plating. Pd ions and Pd complexes were also impregnated, but they did not have the ability to accelerate the plating. Hence, the reduction of $\mathrm{Pd}^{2+}$ into $\operatorname{Pd}(0)$ was investigated using an aqueous solution of $\mathrm{NaBH}_{4} 12$ or using $\mathrm{H}_{2}$ gas $13 . \mathrm{NaBH}_{4}$ was also used before impregnation to smooth the surface of the film and thus avoid the clustering of Pd. These two approaches were adopted with the purpose of rendering uniform the plated metal layer as well as improving its adhesive property.

\section{Experimental}

\subsection{Materials}

Aramid film (thickness : $16 \mu \mathrm{m}$ ) was provided by Teijin Advanced Films, Ltd. $\mathrm{CO}_{2}$ (purity : $+99.99 \%$ ) was purchased from Uno Oxygen Co. and used as received. Palladium (II) acetylacetonate $\left(\mathrm{Pd}(\mathrm{acac})_{2}\right)$ was purchased from Tokyo Chemical Industry, and palladium(II) hexafluoroacetylacetonate $\left(\operatorname{Pd}(\mathrm{hfa})_{2}\right)$ was purchased from Sigma-Aldrich; both were used without further purification.

Sodium tetrahydroborate $\left(\mathrm{NaBH}_{4}\right)$ was acquired 
1) $\left[\mathrm{H}_{3} \mathrm{C}_{2}^{-\mathrm{O}_{3} \mathrm{C}}\right]_{2}^{\mathrm{Pd}}$

2)

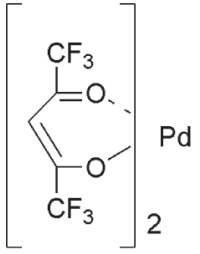

Fig. 1 Organometallic complexes : 1) $\mathrm{Pd}(\mathrm{acac})_{2}$ and 2) $\operatorname{Pd}(\mathrm{hfa})_{2}$

from Wako Pure Chemical Industries, Ltd. and used as received. The electroless copper plating solutions were ATS-ADDCOPPER IW-A, ATS-ADDCOPPER IW-M and ATS-ADDCOPPER IW-C (Okuno Chemical Industry Co., Ltd.)

\subsection{Methods}

Figure 2 illustrates the sc- $\mathrm{CO}_{2}$ apparatus, in which each sample was impregnated with one of the organometallic complexes as a pre-treatment.

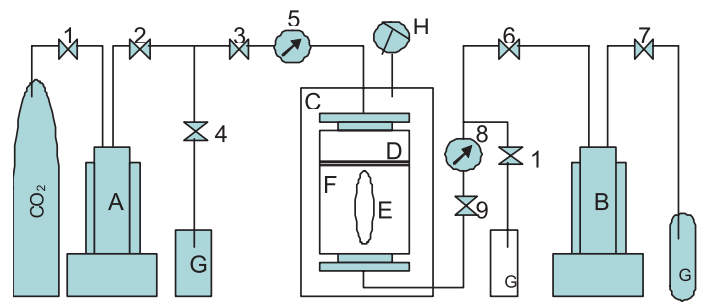

Fig. 2 Illustration of the reaction apparatus. (A) Syringe pump, (B) cleaning pump, (C) heater and high-pressure stainless-steel vessel, (D) organometallic complex, (E) sample, (F) sample cartridge, $(\mathrm{G})$ washing solvent, $(\mathrm{H})$ thermometer, (I) glass filter, $(1,2,3,4,6,7,9,10)$ valves, and $(5,8)$ pressure gauges.

\subsubsection{Supercritical pretreatment}

All experiments were performed in a batch-type supercritical extractor (SFE System 2000 ; ISCO, USA). A simplified scheme of the experimental procedure is shown in Figure 3. The aramid film was cut into $1.5 \mathrm{~cm}$ $5.0 \mathrm{~cm}$ or $5.0 \mathrm{~cm} 5.0 \mathrm{~cm}$ pieces. Sample impregnation was conducted in a $10-\mathrm{cm}^{3}$ cartridge that was sealed with two plugs, one at the entrance for sc- $\mathrm{CO}_{2}$ and the other at a high-pressure needle valve. The cartridge was set up as follows: a glass filter was placed at the bottom; the sample was placed above it, followed by two glass filters with a specific amount of organometallic complex between the filters. The complex was introduced in excess relative to the average solubility of the metal complex and the amount absorbed by the aramid film. The amount depended on the duration of impregnation. When the thermoregulated heater reached $150^{\circ} \mathrm{C}$, the

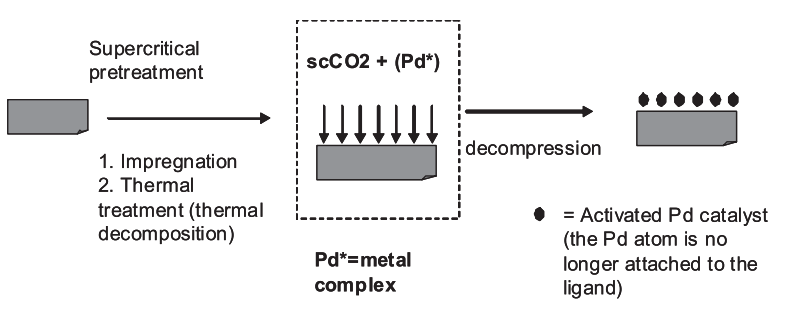

Fig. 3 Schematic diagram illustrating the processes of supercritical pre-treatment (impregnation, thermal treatment, decompression).

cartridge was inserted, and the pre-treatment was conducted from 30 minutes to 7 hours for $\operatorname{Pd}(\mathrm{acac})_{2}$ and for 3 hours or 30 minutes for $\mathrm{Pd}(\mathrm{hfa})_{2}$. The temperature and pressure of impregnation were kept constant for the duration of the treatment. When the impregnation was finished, the cartridge was decompressed by releasing the $\mathrm{CO}_{2}$, then the cartridge was extracted from the heater.

\subsubsection{Treatment with $\mathrm{NaBH}_{4}$}

The pre-treatment consisted in dipping the aramid film sample into a $1 \mathrm{~mol} / \mathrm{L}$ water solution of $\mathrm{NaBH}_{4}$ for 10 or 20 minutes under manual stirring. For the reduction treatment, aramid film impregnated with palladium complex was dipped into a solution with the same concentration for 1,5 or 10 minutes.

\subsubsection{Treatment with $\mathbf{H}_{2}$}

Aramid film impregnated with one organometallic complex was reduced by $\mathrm{H}_{2}$ gas for 1,5 or 10 minutes at $150^{\circ} \mathrm{C}$ and 0.5 bar. The $\mathrm{H}_{2}$ gas was in large excess.

\subsubsection{Electroless copper plating}

The electroless plating method was used for the metal plating process (Fig. 4). The electroless copper plating solution was created by adding $10 \mathrm{~mL}$ of ATSADDCOPPER IW-A to $172 \mathrm{~mL}$ of deionized water, followed by the addition of $16 \mathrm{~mL}$ of ATS-ADDCOPPER IW-M and $2 \mathrm{~mL}$ of ATS-ADDCOPPER C. The impregnated aramid film was dipped into the electroless copper plating solution at $42^{\circ} \mathrm{C} \pm 2^{\circ} \mathrm{C}$ until a homogeneous metal layer was formed on its surface or until the metal layer began to peel off. To achieve proper mixing and to avoid damaging the sample, the solution was stirred manually.

\subsection{Analyses}

The adhesive strength of the plated metal layer after

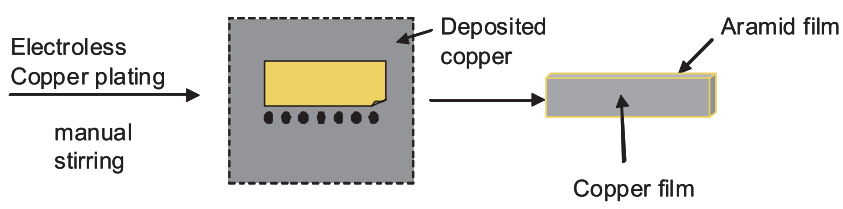

Fig. 4 Schematic diagram of the electroless deposition of copper onto aramid film by manual stirring. 
electroless copper plating was evaluated by the cellophane tape method. A piece of cellophane tape was stuck on the plated metal layer. The pressure applied to stick the tape was the same for each test. Then, the piece of tape was pulled off. The adhesive strength of metal layer was evaluated visually according to the scale shown in Table 1.

Table 1 Evaluation scale for the adhesive strength of the plated metal layer.

\begin{tabular}{|c|c|c|c|}
\hline 00 & 0 & $\times$ & $x \times$ \\
\hline $\begin{array}{c}\text { No metal } \\
\text { on the tape: } \\
\text { adhesion is } \\
\text { strong. }\end{array}$ & $\begin{array}{l}\text { Few small } \\
\text { specks of } \\
\text { metal on } \\
\text { the tape: } \\
\text { adhesion is } \\
\text { not strong } \\
\text { enough. }\end{array}$ & $\begin{array}{c}\text { Large } \\
\text { specks of } \\
\text { metal on } \\
\text { the tape: } \\
\text { adhesion is } \\
\text { low. }\end{array}$ & $\begin{array}{l}\text { All the } \\
\text { plated } \\
\text { metal is on } \\
\text { the tape: no } \\
\text { adhesion. }\end{array}$ \\
\hline
\end{tabular}

X-ray photoelectron spectroscopy (XPS) was conducted on a ULVAC 5500 spectrometer with $\mathrm{Mg}-\mathrm{K}_{\alpha}$ excitation. The settings were $100 \mu \mathrm{m}, 300 \mathrm{~W}$ and $15 \mathrm{kV}$ under a vacuum pressure of $110^{-8} \mathrm{~Pa}$. Before the XPS analysis, each sample was placed in a vacuum oven at $40^{\circ} \mathrm{C}$ for a minimum of 12 hours. Scanning electron microscopy (SEM) was carried out on a Hitachi S-2600H microscope at an accelerating voltage of $15 \mathrm{kV}$.

\section{Results and discussion}

\subsection{Optimal impregnation time for $\operatorname{Pd}(\text { acac })_{2}$}

Since no literature could be found on the impregnation of $\mathrm{Pd}(\mathrm{acac})_{2}$ into aramid film, it was necessary to determine the time of impregnation for that complex. Our study focused on the time only, in order to be able to compare the efficiency of aramid film plating after impregnation of $\mathrm{Pd}(\mathrm{hfa})_{2}$ and $\mathrm{Pd}(\mathrm{acac})_{2}$. Aramid film was impregnated with $\operatorname{Pd}(\text { acac })_{2}$ in large excess relative to the average solubility of the metal complex and the amount absorbed by the aramid film, so that the time of impregnation would not be influenced by a lack of complex during the process. The process lasted from 30 minutes to 7 hours. The efficiency of the impregnation was checked by performing electroless copper plating in the conditions explained in Section 2.2.3.

From the 3-hour impregnation, it was possible to obtain a shiny copper-colored plated layer on the aramid film. Therefore, it was possible to conclude that the impregnation of $\operatorname{Pd}(\mathrm{acac})_{2}$ is optimal when it lasts for 3 hours at $150^{\circ} \mathrm{C}$ and $15 \mathrm{MPa}$. The second part of this study focused on the improvement of the adhesive property of the plated copper layer based on these optimal impregnation conditions. The cellophane tape method applied to the films after plating revealed that the plating was indeed homogeneous but that the adhesion strength was lower than the standard industrial requirements.

\subsection{Improvement of the metal plating}

Once it was possible to plate aramid films homogeneously, it was necessary to focus on the improvement of the copper layer adhesion.

Aramid film was subjected to a two- or three-step treatment. The optional treatment was the reaction with the reducing agent, $\mathrm{NaBH}_{4}$.

Both complexes were impregnated for 3 hours at $150^{\circ} \mathrm{C}$ and $15 \mathrm{MPa}$.

The film's aspect was not changed by any of the treatments (treatment with $\mathrm{NaBH}_{4}$ or impregnation of a metal complex). It retained its shiny yellow color and flexibility.

In the first trial, the samples were plated for 40 seconds and acquired a homogeneous copper layer. Even if 15 minutes is the recommended time for the electroless plating process, quick plating can endow the metal layer with properties more suitable for industrial application (homogeneity, high adhesive strength). Hence, the next samples were subjected to electroless copper plating until a uniform copper layer was formed on both sides or until the first signs of metal peeling off appeared.

\subsubsection{Surface treatment with $\mathrm{NaBH}_{4}$}

Charbonnier and co-workers 14 described that the surface of a polymer became smooth and regular after reduction using $\mathrm{NaBH}_{4}$. Our idea was to use $\mathrm{NaBH}_{4}$ to smooth the surface of aramid film in order to avoid the formation of $\mathrm{Pd}$ clusters during the metal complex impregnation. In this way, the plating might start after a shorter time lag and at the same time everywhere on the surface of the film, thus leading to the formation of a homogeneous metal layer. So, we tried this method on aramid film treated with $\mathrm{NaBH}_{4}$ for 10 and 20 minutes. Images of the surface obtained with an electronic microscope are shown in Figure 5.

The $\mathrm{NaBH}_{4}$ treatment retarded the start of the electroless plating process. In addition, copper was deposited on random spots of the surface, and even after 15 minutes of plating, it was not possible to obtain a homogeneous layer on both sides of the aramid film. Moreover, the adhesion of the plated copper on the 

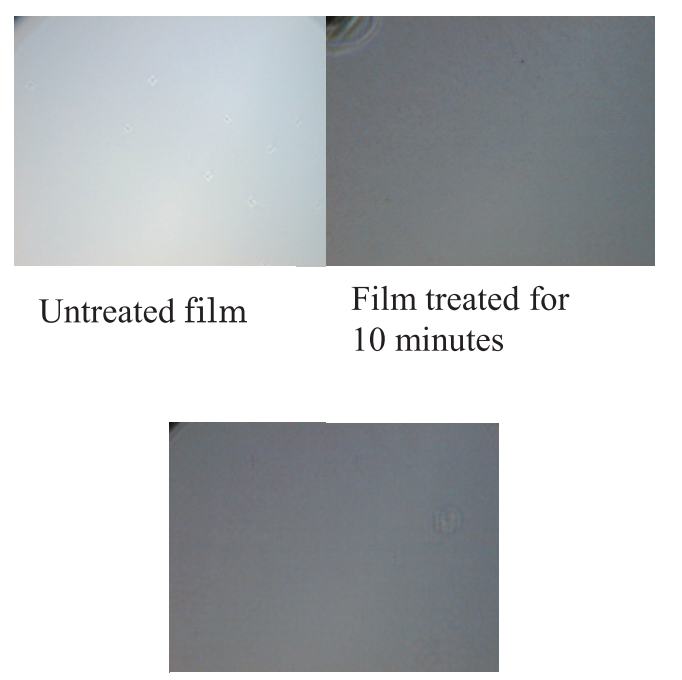

Film treated for 20 minutes

Fig. 5 Microscope images of the surface of aramid film before and after treatment with $\mathrm{NaBH}_{4}$.

surface of the film did not improve, and in some cases the adhesion deteriorated. The percentage of copper coverage of the aramid film after impregnation is also interesting. Even if the plating is not homogeneous on the film treated with $\mathrm{NaBH}_{4}$, the percentage of copper coverage is more important. The SEM images (Fig. 6) show cracks of the copper layer plated on the aramid film treated with $\mathrm{NaBH}_{4}$. Clusters of copper are also present on the surface of the metal. Therefore, it is reasonable to assume that the copper was continuously deposited on the same spots, and because the copper layer at those spots became too thick, the interaction between the film and the layer was not strong enough to keep the copper attached to the film. Thus, cracks appeared when the tension between the polymer and the metal layer became too strong.

Based on these findings, it might be thought that the auto-catalysis reaction occurring in the electroless plating solution starts with difficulty due to the lack of $\mathrm{Pd}$ catalyst. Indeed, the pre-treatment with $\mathrm{NaBH}_{4}$ might interfere with the impregnation of the organometallic complex and prevent the penetration of the catalyst into the aramid film. These comments are valid for both complexes, $\operatorname{Pd}(\text { acac })_{2}$ and $\operatorname{Pd}(\text { hfa })_{2}$.

Only four samples achieved strong adhesion. All of them were impregnated with $\mathrm{Pd}(\mathrm{acac})_{2}$. In addition, those samples had a short electroless plating time due to a homogeneous and fast start. Hence, the results of our study agree with those obtained by Charbonnier et al . 14, who mentioned that a short time lag is the main factor for obtaining a homogeneous metal layer with a strong adhesion. Nevertheless, if the dipping time in the

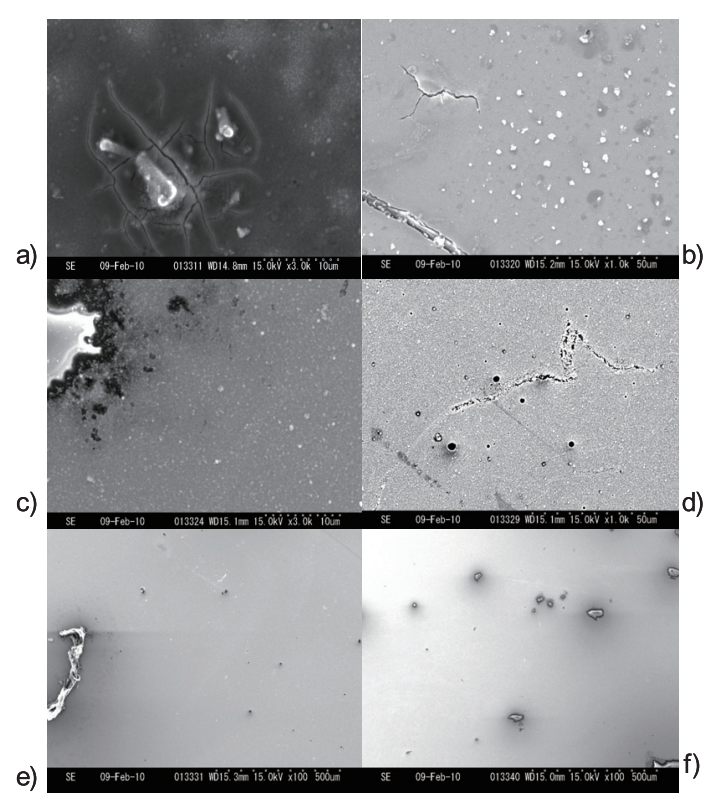

Fig. 6 SEM images of the copper layer on aramid film pre-treated with $\mathrm{NaBH}_{4}\left(\mathrm{a}: \mathrm{Pd}(\mathrm{acac})_{2}\right.$ at $12 \% \mathrm{w}$. o.f; b : $\operatorname{Pd}(\mathrm{acac})_{2}$ at $8 \%$ w.o.f; c) $\mathrm{Pd}(\mathrm{hfa})_{2}$ at $12 \%$ w.o.f impregnated for 3 hours; d) $\mathrm{Pd}(\mathrm{hfa})_{2}$ at $20 \%$ w.o.f impregnated for 3 hours; e) $\mathrm{Pd}$ $(\mathrm{hfa})_{2}$ at $12 \%$ w.o.f impregnated for 30 minutes ; f) $\mathrm{Pd}(\mathrm{hfa})_{2}$ at $20 \%$ w.o.f impregnated for 30 minutes).

electroless solution is too short, the layer is almost translucent and therefore cannot confer useful properties (conductivity, electromagnetic shield) to the film. According to these observations, a balance has to be struck between the adhesion strength and the thickness of the plated layer. In this study, we found the optimal dipping time to be around 1 to 2 minutes. Regarding the samples treated by $\mathrm{Pd}(\mathrm{hfa})_{2}$, the plating was not efficient under the same conditions (12\% w.o.f. of complex for 3 hours at $150^{\circ} \mathrm{C}$ and $15 \mathrm{MPa}$ ) of impregnation. Even if the amount of complex was increased to $20 \%$ w.eight of fabric (w.o.f), the plating was still not efficient, and it was not possible to obtain a homogeneous metal layer on the aramid film. However, it has been observed that $\operatorname{Pd}(\mathrm{hfa})_{2}$ is less stable than $\mathrm{Pd}(\mathrm{acac})_{2}$ in a sc- $\mathrm{CO}_{2}$ environment, so we tried to impregnate it for 30 minutes under the same conditions of temperature $\left(150^{\circ} \mathrm{C}\right)$ and pressure $(15 \mathrm{MPa})$. Those changes led to a more uniform plating, but the dipping time was still too long to ensure a strong adhesion of the plated layer.

\subsubsection{Reduction reaction}

During $\mathrm{sc}-\mathrm{CO}_{2}$ treatment, the organometallic complex undergoes thermal decomposition and $\mathrm{Pd}$ is impregnated into the aramid film. Pd is the main catalyst for the electroless copper plating. However, not only Pd metal is impregnated, but also $\mathrm{Pd}(\mathrm{II})$, which does not 
catalyze the plating. By reducing the Pd ions, the amount of $\operatorname{Pd}(0)$ might be increased, which would enable the electroless copper plating to start faster and thus lead to the formation of a more homogeneous metal layer with a greater adhesion strength. Regarding the conclusions drawn in the previous section, $\operatorname{Pd}(\mathrm{hfa})_{2}$ was impregnated for 30 minutes.

\subsubsection{Reduction agent : $\mathrm{NaBH}_{4}$}

$\mathrm{NaBH}_{4}$ is a strong reduction agent that has been used to reduce ions into metals, which then react with $\mathrm{Cu}$ ions in the electroless plating process 15 . The nature of its reduction of $\mathrm{Pd}$ has been described by Zhao, X. 16 . $\mathrm{NaBH}_{4}$ in aqueous solution liberates $\mathrm{Na}^{+}$and $\mathrm{BH}_{4}^{-}$, which belongs to the redox couple $\mathrm{B}(\mathrm{OH})_{4}{ }^{-} / \mathrm{BH}_{4}{ }^{-}\left(\mathrm{E}_{0}=-1.24 \mathrm{~V}\right.$ at $\mathrm{pH}=14)$. Its decomposition reaction is as follows :

$$
\mathrm{BH}_{4}^{-}+8 \mathrm{OH}^{-} \rightarrow \mathrm{B}(\mathrm{OH})_{4}^{-}+4 \mathrm{H}_{2} \mathrm{O}+8 \mathrm{e}^{-} \text {. }
$$

Combined with the half-reaction equations of the redox couple of $\mathrm{Pd}\left(\mathrm{Pd} / \mathrm{Pd}^{2+} ; \mathrm{E}_{0}=0.915 \mathrm{~V}\right)$ and $\mathrm{BH}_{4}^{-}$, the reaction occurring in the reduction solution could be represented as follows :

$$
\mathrm{BH}_{4}{ }^{-}+8 \mathrm{OH}^{-}+4 \mathrm{Pd}^{2+} \rightarrow \mathrm{B}(\mathrm{OH})_{4}^{-}+4 \mathrm{H}_{2} \mathrm{O}+\mathrm{Pd} .
$$

According to Ma et al . 17, the XPS Pd 3d core-level is a doublet ( $\mathrm{Pd} 3 \mathrm{~d}_{5 / 2}$ and $\left.\mathrm{Pd} 3 \mathrm{~d}_{3 / 2}\right)$ lying at about 338 and $343 \mathrm{eV}$. Moreover, they observed that the doublet at that energy ensures the presence of $\mathrm{Pd}(\mathrm{II})$. As shown by the XPS spectra (Fig. 7), the aramid film impregnated with $\mathrm{Pd}(\mathrm{hfa})_{2}$ was impregnated with $\operatorname{Pd}(0)$ and $\mathrm{Pd}(\mathrm{II})$ as well, with a predominance of $\mathrm{Pd}(\mathrm{II})$ (spectrum (a), blue curve). The reduction treatment of the aramid film led to a decrease in the amount of $\mathrm{Pd}(\mathrm{II})$ and an increase in the amount of $\operatorname{Pd}(0)$ (spectrum (a), yellow, pink and turquoise curves). Regarding the XPS spectra of $\operatorname{Pd}(\mathrm{acac})_{2}$ (spectrum (c)), the amount of Pd species impregnated, Pd (0) and $\mathrm{Pd}(\mathrm{II})$, was around three time higher than the amount of $\operatorname{Pd}(\mathrm{hfa})_{2}$. Nevertheless, it was more difficult to determine the main species impregnated. In the case of Pd $(\text { acac) })_{2}$ (spectrum (c)), a small doublet is observed at around 332 and $336 \mathrm{eV}$. It might correspond to $\mathrm{PdO}$ and $\mathrm{PdO}_{2}$, respectively, which might be due to the oxidation of $\mathrm{Pd}$ after reduction.

Even if the XPS analyses confirm the efficiency of the reduction of $\operatorname{Pd}(\mathrm{II})$ into $\operatorname{Pd}(0)$, which is the catalyst of electroless copper plating, the plating was not accelerated, and therefore the amount of copper deposited on the surface of the film was still excessive, making it impossible to achieve the adhesive strength required by the industry standard. Moreover, the SEM pictures (Fig. 8) show that the surface of the copper layer has major defaults, especially scratches and cracks.

\subsubsection{Reduction agent : $\mathrm{H}_{2}$ gas}

Another way of reducing $\mathrm{Pd}(\mathrm{II})$ before electroless copper plating is to use $\mathrm{H}_{2}$ gas. Indeed, the redox couple $\mathrm{H}_{2} / \mathrm{H}^{+}$has a redox potential equal to $0 \mathrm{~V}$; therefore, $\mathrm{H}_{2}$ can react with $\operatorname{Pd}^{2+}\left(\mathrm{E}^{0}=0.915 \mathrm{~V}\right)$, as shown by the following reactions :

$$
\begin{array}{ll}
\mathrm{Pd}^{2+}+2 \mathrm{e}^{-} \leftrightarrow \mathrm{Pd} & \mathrm{E}^{0}=0.915 \mathrm{~V} \\
\mathrm{H}_{2(\mathrm{~g})} \leftrightarrow 2 \mathrm{H}^{+}+2 \mathrm{e}^{-} & \mathrm{E}^{0}=0 \mathrm{~V} \\
\mathrm{Pd}^{2+}+\mathrm{H}_{2(\mathrm{~g})} \rightarrow \mathrm{Pd}+2 \mathrm{H}^{+} &
\end{array}
$$

The XPS spectra (Fig. 7) show that the characteristic doublet corresponding to the Pd $3 \mathrm{~d}$ core-level $\left(\mathrm{Pd} 3 \mathrm{~d}_{5 / 2}\right.$ and $\mathrm{Pd} 3 \mathrm{~d}_{3 / 2}$ ) was present at about 338 and $343 \mathrm{eV}$. Moreover, the reduction of both complexes, $\operatorname{Pd}(\mathrm{hfa})_{2}$ and $\operatorname{Pd}(\text { acac })_{2}$, occurred. The $\operatorname{Pd}(\mathrm{II})$ peak decreased as the peak corresponding to $\mathrm{Pd}(0)$ was increasing. As observed previously, the amount of $\operatorname{Pd}(0)$ and $\operatorname{Pd}($ II) was larger in the case of $\operatorname{Pd}(\mathrm{acac})_{2}$. This might be explained by the fact that $\mathrm{Pd}(\mathrm{hfa})_{2}$ has a high solubility in sc- $\mathrm{CO}_{2}$ and therefore a lower partition into the aramid film. Consequently, the polymer cannot absorb as much $\operatorname{Pd}(\mathrm{hfa})_{2}$ as it can absorb $\operatorname{Pd}(\text { acac })_{2}$. The XPS analyses demonstrate that a lower rate of reduction was obtained in the 5-minute treatment for $\operatorname{Pd}(\mathrm{hfa})_{2}$ and the 10 -minute treatment for $\operatorname{Pd}(\mathrm{acac})_{2}$, with both reduction agents. Regarding the impact of the reduction on the electroless copper plating, it has to be performed to the end of the conventional time of 15 minutes. Therefore, in the case of $\mathrm{H}_{2}$ as well, the amount of copper plated on the surface of the aramid film was too great for the adhesive property to be satisfactory. In addition, the SEM images (Fig. 9) show scratches, cracks and clusters of copper at the surface of the plated layer. Nevertheless, the reduction achieved with $\mathrm{H}_{2}$ might be gentler than the one with $\mathrm{NaBH}_{4}$, considering that the surface of aramid film treated with $\mathrm{H}_{2}$ was less faulty after plating.

\section{Conclusion}

As a first step, this study determined the ideal impregnation conditions for $\mathrm{Pd}(\mathrm{acac})_{2}$ and optimized those for $\mathrm{Pd}(\mathrm{hfa})_{2}$. It was then possible to establish the influence of three treatments on the adhesive property of the plated copper layer. The surface of the aramid film was smoothed to prevent the formation of catalyst cluters during the impregnation of the organometallic complex. Next, $\mathrm{NaBH}_{4}$ and $\mathrm{H}_{2}$ were utilized as reduction agents to the Pd catalyst at the surface of the film, to improve the adhesion of the metal layer of electroless copper. Both 

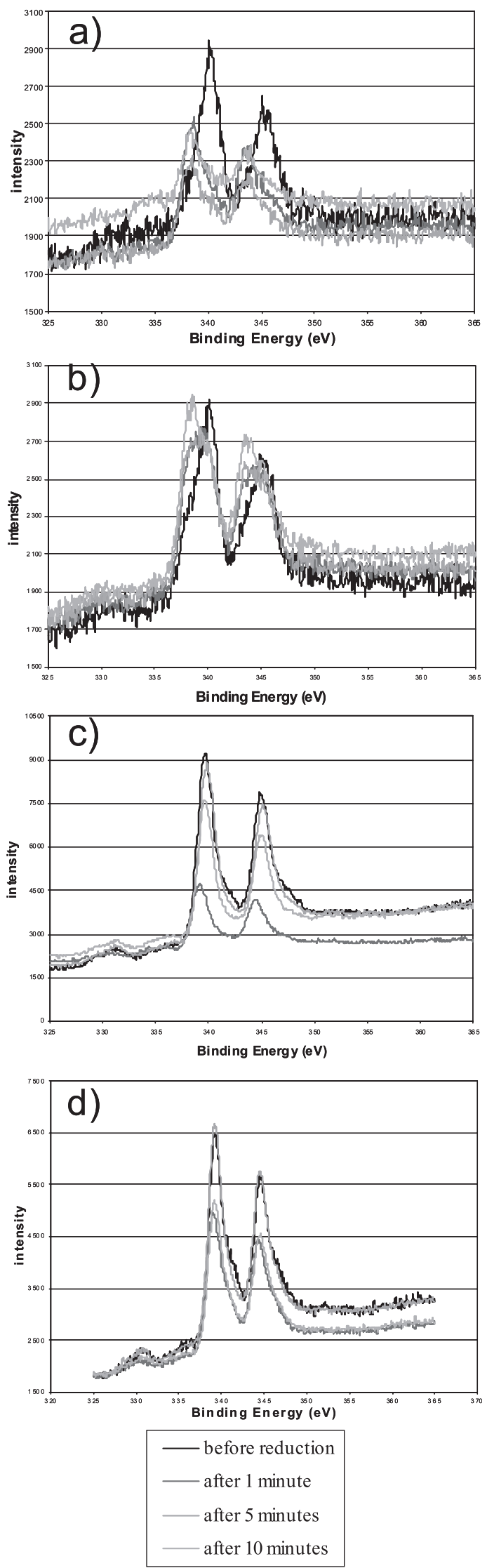

Fig. 7 XPS spectra of the Pd peaks of aramid film impregnated with $\mathrm{Pd}(\mathrm{hfa})_{2}$ and reduced by $\mathrm{NaBH}_{4}$ (a) or $\mathrm{H}_{2}$ (b) and aramid films impregnated with $\mathrm{Pd}(\mathrm{acac})_{2}$ and reduced by $\mathrm{NaBH}_{4}$ (c) or $\mathrm{H}_{2}$ (d).

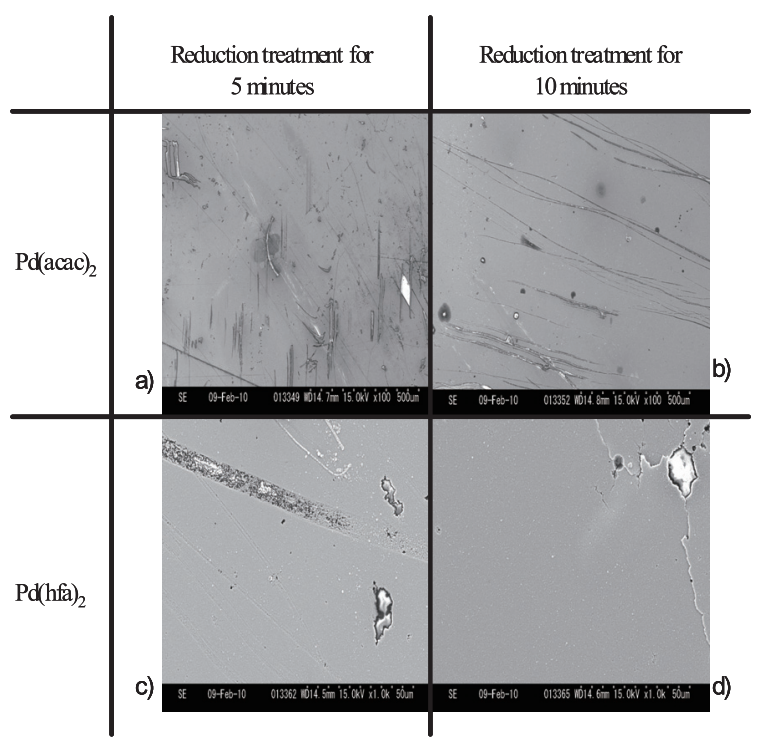

Fig. 8 SEM images of copper-plated aramid film reduced by $\mathrm{NaBH}_{4}$.

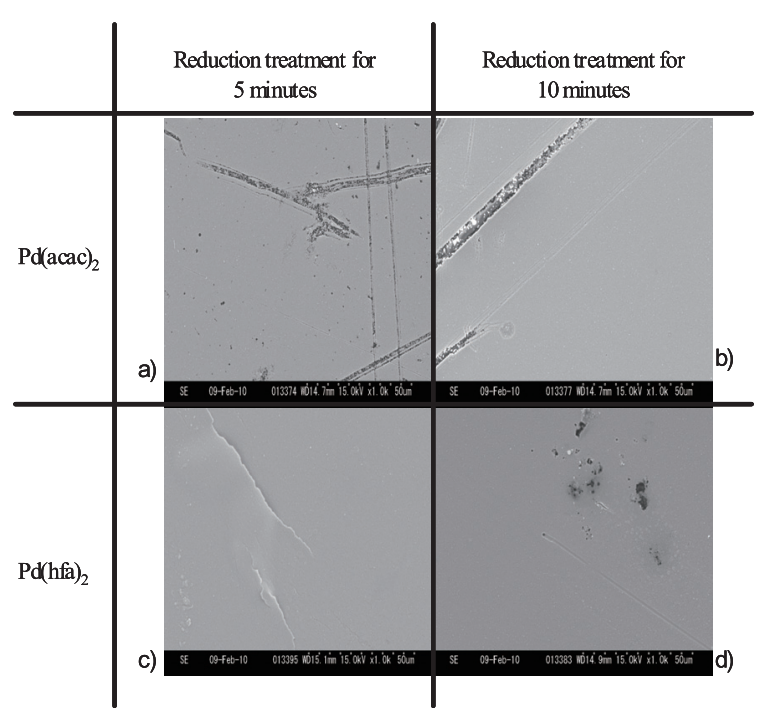

Fig. 9 SEM images of copper-plated aramid film reduced by $\mathrm{H}_{2}$.

agents improved the plating; indeed, it was possible to deposit a uniform copper layer on the film. Nevertheless, the layer did not reach the industrial standard regarding the adhesive property.

In future studies, it is necessary to investigate the influence of thermal treament on the impregnated $\mathrm{Pd}$ catalyst and on the plated metal layer. The idea is to try to increase the amount of catalyst by having a second thermal decomposition and also to observe the influence of the water present in the aramid film.

\section{References}

1. S. Griehl, T. Müller, R. Winkler, Surface and Coatings Technology, 169-170, 24 (2003).

2. D.M. De Leeuw, P.A. Kraakman, P.F.G. Bongaerts, 
C.M.J. Mutsaers, D.B.M. Klaassen, Synthetic Metals, 66-3, 263 (1994).

3. H. Adachi, K. Taki, S. Nagamine, A. Yusa, M. Ohshima, The Journal of Supercritical Fluids, 49-2, 265 (2009).

4. B.S. Yang, Resources, Conservation and Recycling, 16-1-4, 93 (1996).

5. M. Herva, A. Franco, S. Ferreiro, A. Alvarez, E. Roca, Journal of Hazardous Materials, 156 (2008), 478-487

6. X. Ren, Journal of cleaner Production, 8, 473 (2000).

7. C. D. Wood, B. Tan, H. Zhang, A. I. Cooper, in : T. Letcher, (Eds.), Thermodynamics, Solubility and Environmental Issues, Stratton on the Fosse, UK, 383 (2007)

8. H. İçen, M. Gürü, The Journal of Supercritical Fluids, 50- 3, 225 (2009).

9. M. Van der Kraan, V. Fernandez Cid, G. F. Woerlee, W. J. T. Veugelers, G. J. Witkamp, The Journal of Supercritical Fluids, 40-3, 470 (2007).
10. O. Muth, Th. Hirth, H. Vogel, The Journal of Supercritical Fluids, 17-1, 65 (2000).

11. I. Kikic, F. Vecchione, Supercritical impregnation of polymers, 7, 399 (2003)

12. T. Takenouchi, J. Yoshiike, S-I. Wakabayashi, Journal of The Surface Finishing Society of Japan, 57-4, 296 (2006).

13. A. Barrera, M. Virniegra, P. Bosh, V.H. Lara, S. Fuentes, Pallied catalysis $B \sim$ : environmental, 34, 97 (2001).

14. M. Charbonnier, M. Romand, Y. Goepfert, D. Léonard, M. Bouadi, Surface \& Coatings Technology, 200, 5478 (2006).

15. M. Seita, M. Kusaka, H. Nawafune, S. Mizumonoto, Plating Surface Finishing, 83, 57 (1996).

16. X. Zhao, K. Hirogaki, I. Tabata, S. Okubayashi, T. Hori, Surface and Coatings Technology, 201, 628 (2006).

17. Z.H. Ma, K.L. Tan, E.T. Kang, Synthetic metals, 114, 17 (2000). 